\title{
Financial Convergence as a Mechanism for Modifying Sectors of the Global Financial Services Market
}

\author{
Vitalii Rysin $^{1, *}$, Oksana Galenko ${ }^{2}$, Nina Duchynska ${ }^{3}$, Nataliia Kara ${ }^{4}$, Oleksii Voitenko ${ }^{5}$, Alla Shalapak ${ }^{2}$ \\ ${ }^{1}$ Department of Finance, Lviv Polytechnic National University, Lviv, Ukraine \\ ${ }^{2}$ Department of International Accounting and Audit, Kyiv National Economic University, Kyiv Ukraine \\ ${ }^{3}$ Department of International Economics and World Finance, Oles Honchar Dnipro National University, Dnipro, Ukraine \\ ${ }^{4}$ Department of Management and International Business, Lviv Polytechnic National University, Ukraine \\ ${ }^{5}$ Department of International Economic Relations, Ternopil National Economic University, Ternopil, Ukraine
}

Received December 9, 2020; Revised January 11, 2021; Accepted February 18, 2021

\section{Cite This Paper in the following Citation Styles}

(a): [1] Vitalii Rysin, Oksana Galenko, Nina Duchynska, Nataliia Kara, Oleksii Voitenko, Alla Shalapak, "Financial Convergence as a Mechanism for Modifying Sectors of the Global Financial Services Market," Universal Journal of Accounting and Finance, Vol. 9, No. 1, pp. 65 - 73, 2021. DOI: 10.13189/ujaf.2021.090107.

(b): Vitalii Rysin, Oksana Galenko, Nina Duchynska, Nataliia Kara, Oleksii Voitenko, Alla Shalapak (2021). Financial Convergence as a Mechanism for Modifying Sectors of the Global Financial Services Market. Universal Journal of Accounting and Finance, 9(1), 65 - 73. DOI: 10.13189/ujaf.2021.090107.

Copyright $\subseteq 2021$ by authors, all rights reserved. Authors agree that this article remains permanently open access under the terms of the Creative Commons Attribution License 4.0 International License

\begin{abstract}
The relevance of the topic of financial convergence considered in the article is primarily dictated by the intensifying processes of globalization, which generate an increase in competition between participants in the financial market. An essential global trend in the development of the financial services industry has also become the process of increasing interpenetration by different participants of various sectors of the financial market into its other segments due to competition financial convergence. The processes of financial convergence and the formation of new institutional forms of financial associations (financial conglomerates) in the world economy already have a significant impact on the real and financial sectors, public finance and other spheres of the economy. The article examines the prerequisites for the emergence and use of financial convergence by participants in the global financial services market to provide additional competitive advantages and stable development by modifying the established order in the sectors of the financial market. On the example of financial convergence between companies in the insurance and pension sectors, through the creation and participation in financial conglomerates, the main problems of the current
\end{abstract}

state of the global financial market are considered. The article discusses practical ways to determine the presence of financial convergence, based on a modern approach using the methodology for calculating sigma convergence.

Keywords Financial Convergence, Financial Services Market, Global, Sector

\section{Introduction}

The global financial system over the past few decades has experienced a significant number of crises, transformations and changes. Since the emergence of money as a means of payment, the financial services market has come a long way from moneylenders who provided bankrupt kings with loans for campaigns of conquest, to transnational financial conglomerates supporting the development of economic systems of entire continents, from cowrie shells as the first money to virtual cryptocurrencies that exist only as lines of code [9; 12]. 


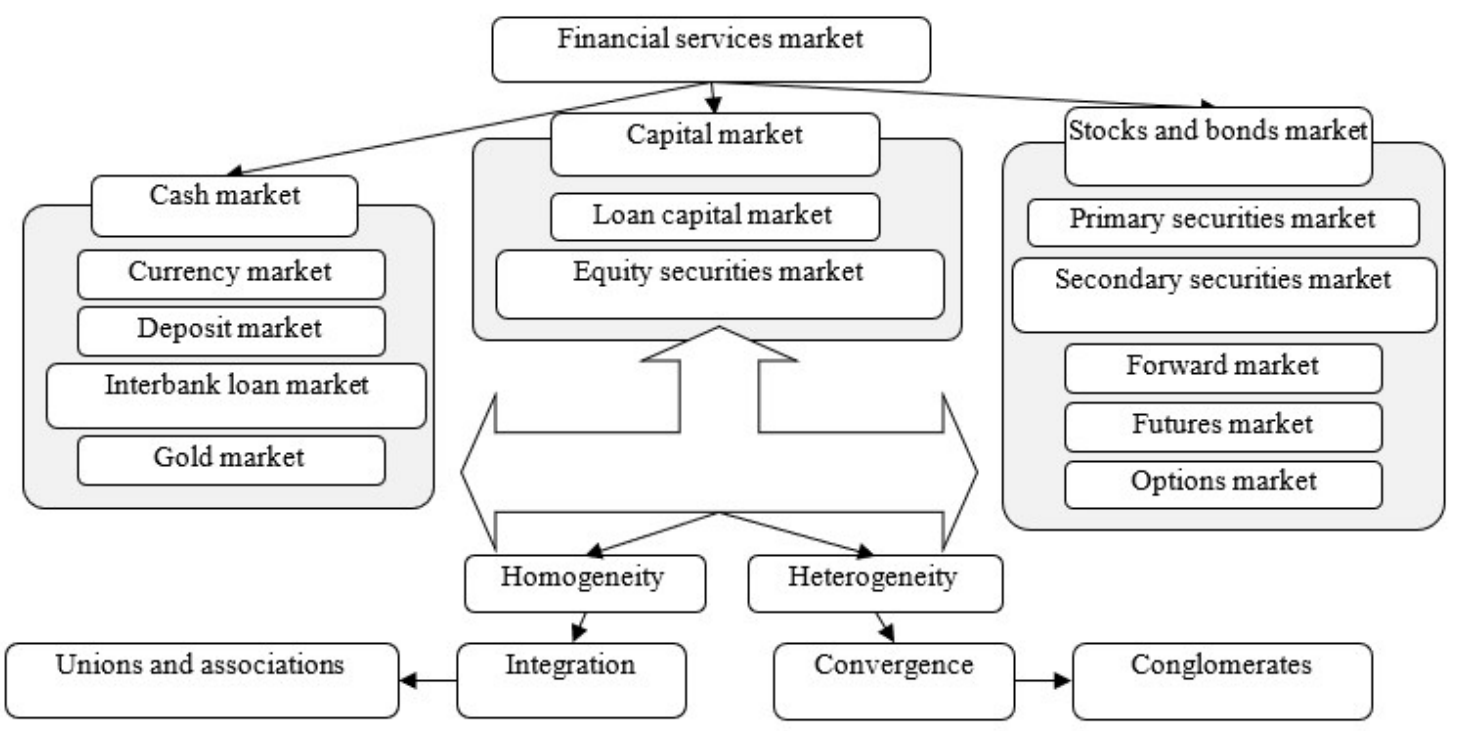

Figure 1. Processes of mutual convergence and integration of various sectors of the financial market

The processes of convergence, as a mechanism of radical integration in the financial services market, began to appear at the beginning of the 20th century but reached their greatest heyday in its second half [8]. It was then that the rapid current of the global practice of globalization in various sectors of the economy, multiplied by the liberalization of state control and regulatory functions and the growing informatization of society, created a favourable environment for the convergence of entities that traditionally worked in various sectors of the financial services market. Schematically, the processes of mutual convergence and integration of different sectors of the financial market are illustrated by the diagram in Fig. 1 .

Speaking about the processes of integration and convergence in financial markets, one should immediately distinguish between these concepts, since, despite their similarity in several features, they are based on fundamentally different approaches [11; 14]. The financial integration of economic entities is based on the observance of the principle of homogeneity, ensuring the homogeneity of components according to individual characteristics, which is an association of equivalent entities, for example, a merger of banks, a merger of insurance companies, pension funds, etc. On the other hand, financial convergence is based on the observance of the principle of heterogeneity, that is, heterogeneity in composition and origin in the functional structures and management strategies are adopted in financial institutions.

The signs of heterogeneity during convergence in the financial market should also include:

- heterogeneity of market entities in aggregate or one of the characteristics;

- heterogeneity of institutions, both in composition and origin;
- heterogeneity of strategic decisions and their adoption in financial institutions of different segments of the financial market;

- heterogeneity in the composition, quality and volume of services included in the financial product $[1 ; 15]$.

\section{Literature Review}

\section{A. Factors and prerequisites for the use of financial convergence as a modifying instrument of the financial market sectors.}

In recent years, there has been a rapid increase in changes in the financial landscape of the global economic arena, the role of financial instruments is increasing, and the influence of participants in the financial services market is increasing [10]. The main factor underlining the strengthening of the role of finance in recent decades is the rapid growth of commodity-money and credit-money relations. There is a trend towards a constant increase in commodity flows both within countries and in the field of international trade, for the service of which it is necessary to increase financial flows similarly. An increase in financial flows, as well as an increasing volume of use of financial instruments, leads to an increase and intensification of competition, both between individual entities and between entire sectors of the financial market. A natural process that allows us to adapt to such conditions is the growth of globalization and financial convergence between the entities involved in the development of the financial services industry in the global financial market [2]. The complexity of the factor and their role in the processes of financial convergence are demonstrated in Fig. 2. 


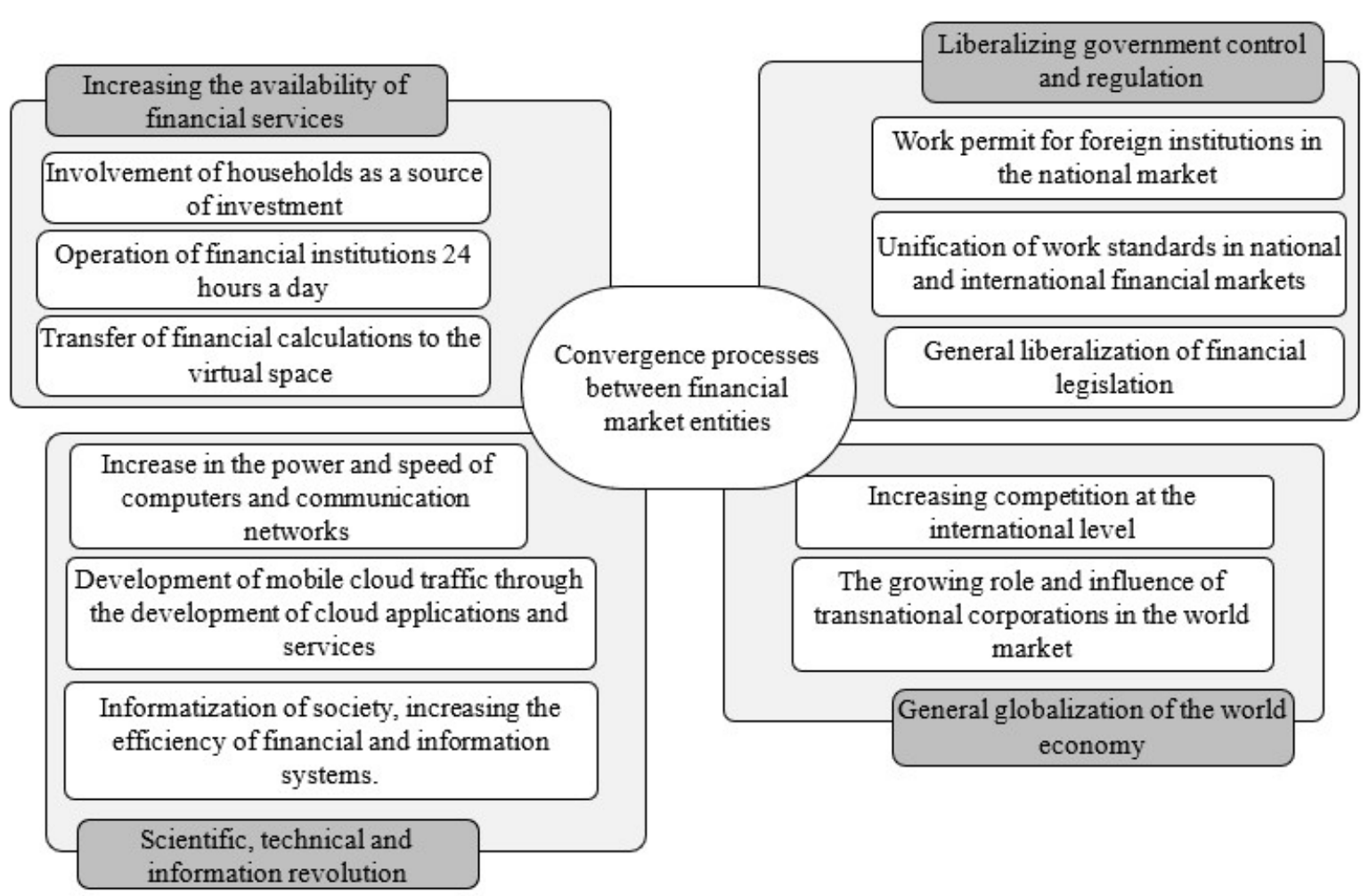

Figure 2. Scheme of factors influencing the growth of convergence in the financial services market

Increased competition, competition for consumers, and the search for new ways to improve economic efficiency make financial convergence a desirable alternative for many large corporations.

The process of increasing interchangeability and interpenetration between different types of financial intermediaries has become very noticeable in the world financial market. Non-bank institutional investors, commercial banks, investment funds, insurance corporations and, of course, pension funds, have increasingly begun to use convergence processes for mutual penetration into non-traditional sectors for themselves.

The factors and reasons for this can be divided into four key groups:

The first factor was the increased availability of financial resources. The growing role of finance in economies with growing commodity-money relations is observed in all markets where there is an increase in commodity flows both within countries and in the field of international trade, which naturally requires an increase in financial flows that serve them.

An additional catalyst was the involvement of households, firms and states in lending operations; the government encouraged the population to increase personal savings, which served as an additional source of investment. This became possible primarily due to the increasing availability of financial services due to:

1. Increasing the efficiency and speed of providing financial services based on the rapid development of information and communication technologies and the use of the Internet, which led to the ability to ensure the operation of financial institutions 24/7.

2. Qualitative shifts in the approach to competition between financial market participants, which led to the transition from the competition based on the affiliation of a specific entity to a particular industry to product competition based on the transformation of financial products and services.

3. Improving the efficiency of financial markets due to increased mobility of international capital.

The second factor ensuring the strengthening of the role of convergence was the strengthening of the role of scientific and technological progress, both in production and in the field of information technology $[1 ; 3 ; 5]$. This factor includes both a revolution in science, a transition to a new technological order, and an information revolution, as well as global changes in society and the growth of informatization of community.

The enormous power of computers, combined with their speed and the speed of networks, creates the preconditions for the transformation of the financial sector because gigantic volumes of information and vast distances are no longer an obstacle to its analysis, systematization and instant transmission.

For the effective operation of financial and information networks, it is also necessary to have a certain critical number of users themselves in the world, and modern society, being included in virtual communication via the Internet, has provided an opportunity for financial 
institutions to do this.

The development of cloud applications and services based on the use of mobile cloud traffic, which allowed an increasing number of mobile Internet users to overcome the limitations imposed by their devices, also provided tremendous prospects for participants in the financial services market.

In such conditions, economic entities providing scientific and technological progress are experiencing an unprecedented demand for financial resources (for new investments and research, for expanding sales markets, and so on). The world financial system, reaping the fruits of their work, is forced to find and use both new sources of financial resources and ways to compete for consumers, for example, by implementing convergence between pension and insurance funds.

New challenges of the modern economy and scientific progress give rise to profound structural changes in the entire financial sector, transforming and modifying whole sectors of the financial market. The role of some types of financial activities and institutions (traditional forms of credit and credit institutions, commercial banks) is decreasing, and the role of others is increasing (non-cash and computerized settlements, the issue of securities and new types of obligations, currency and stock transactions), all these forces participants to look for new ways to continue their activities, which leads them to use convergence as a way to ensure their existence.

The third key factor can be called the processes of liberalization, and the unification of standards of work in the national and international financial markets. This trend can be clearly seen in various sectors of the financial services market. The traditional role of the state as a mentor of the financial market is increasingly losing importance, against the backdrop of the increasing globalization of the economy, and the transition of this role to the sphere of activities of international institutions.

An example of such processes is the liberalization of financial legislation in some countries, which allowed banks and insurance companies to own significant stakes in each other $[1 ; 4 ; 6 ; 14]$.

Likewise, the processes of liberalization and unification have become the reason for the possibility of transforming national financial markets into integral parts of a single world market, based on global rules of work. Several national and international financial organizations to liberalize the world financial market are engaged in the development and implementation of uniform standards and codes of conduct for all areas of financial activity, which, in turn, leads to the acceleration of globalization processes.

The last factor in the strengthening of the role of financial convergence in the global financial services market was the accelerating processes of globalization, both in the real economy and in the financial sector. The process of globalization itself directly involves convergence as a tool, but nevertheless, it is much broader. All over the world and at all strata of modern society, attitudes towards globalization are very ambiguous, but this process itself is in intensive development.

Economic globalization is expressed, first of all, in the ever-growing economic interdependence of national economies around the world as a result of the rapid growth of cross-border movements of goods, services, technologies and capital. At the same time, economic actors, using the mechanisms of globalization and convergence, solve the problems of competitiveness on a global scale.

\section{B. Financial conglomerates as key actors in convergence processes in the financial market.}

Financial convergence, in its essence, is the interpenetration of activities and spheres of interests competing between subjects - participants in different sectors of the global financial market, based on their interconnection and a certain similarity, uniting the efforts of the participants and aimed at jointly simultaneously increasing the competitiveness of these entities.

Convergence as a modification mechanism can be characterized as the penetration of the activities of the subjects of a particular financial sector into the activities of other financial sectors of the world financial market, and this penetration can be carried out on a compulsory or voluntary basis. A forced or aggressive form of convergence is implemented by one of the subjects of a specific sector of the financial market by including in its activities spheres or functions that are originally inherent in other sectors of the financial market, which does not imply the participation of representatives of other sectors in this process. An example of using this form of convergence is the creation of new products that include elements of products from other sectors of the financial market. In such a case, an increase in the share of its participation in the general financial market is due to the seizure by a certain participant of one of the sectors of the financial market of the spheres of activity of other participants, and this additional income due to such aggression mainly goes to the initiator of the seizure.

As an illustrative example, we can cite a variant of the mortgage lending banking product that includes compulsory insurance. Moreover, if insurance is provided by an insurance company independent of the bank, there is no bank penetration into the activities of the insurance sector. If the bank in terms of the contract specifically stipulates the insurance company in which the insurance can be obtained, and at the same time with the relevant insurance company the bank concludes an agreement on the share of its own profit, an aggressive form of convergence will take place. It should be noted that in modern conditions, the use of an aggressive form of convergence is strongly limited due to the licensing of the 
activities of various sectors of the financial market in its pure form.

A second option is a voluntary form of penetration; it is implemented through the pooling of efforts of representatives of different sectors of the financial market, aiming at jointly increasing the share of each of them in it. This form of convergence involves the unification of spheres and functions of representatives of different sectors of the financial market voluntarily.

An example of voluntary financial convergence is the creation of financial conglomerates. Within their framework, the activities of representatives of different sectors of the financial market are united; the income received from such an association (interpenetration) is redistributed among all members of the conglomerate; At the same time, the share of participation of representatives of different sectors of the financial market, who are members of the conglomerate, increases (does not decrease). In the financial market itself, each of the sectors is modified, due to the peculiar development of the boundaries of their activities and the expansion of interests and spheres of influence of the participants. The place of such financial conglomerates in the financial services market is clearly illustrated by Fig. 3 .

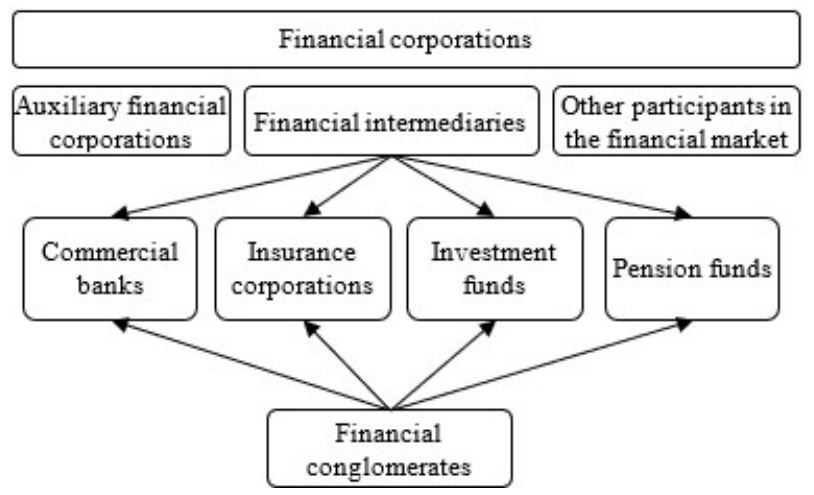

Figure 3. Place of financial conglomerates in the global financial services market

A feature of financial convergence is that its participants are subjects of various sectors of the financial market, previously competing with each other. However, with an aggressive form of convergence, competition between its participants remains, only its conditions change, and the initiator of the intersection receives most of the income from it. In a voluntary form of convergence, the efforts of its participants are combined; in the market, subjects united by convergence act as a single entity, therefore, competition moves to the next, higher level. In this case, all participants receive income from the interpenetration of the activities of the subjects.

The active process of creating financial conglomerates, as the basis for joint development and survival, began after the participants in the financial services market realized that narrow specialization carries potentially more risks than the risks of expanding into new sectors of the financial market. Financial services market participants, represented by commercial banks, insurance corporations, investment and pension funds, aim to form financial conglomerates to improve their competitive advantages [7; 13].

First of all, as noted above, this is due to the impossibility of enhancing their competitiveness only at the expense of their resources in the context of globalization. The appearance on the financial market of large players operating at the world level and possessing incomparably massive resources and capabilities makes the creation of a financial conglomerate almost the only possible development strategy. In a competitive confrontation between national and world participants in the financial services market, they have a greater chance of winning, only those participants of the national financial market who have timely united their efforts, and even greater synergistic effect will be obtained by participants - subjects of different sectors of the national financial market, using financial convergence. The methods of uniting market participants into a financial conglomerate are different, just as the institutions that regulate and control their activities are presented in Fig.4, the most obvious ones.

Observing the evolutionary development of participants in the financial services market, you can see how a gradual change in their structure is taking place: from specialized entities - insurance corporations, brokers, various investment and credit banks, investment funds - to integrated financial associations - financial conglomerates, where multiple types of entities are included as a component. The joint activity of financial conglomerates assumes that they not only bear the costs associated with the transfer of resources from one institutional unit to another but also assume the risks of these subjects of the financial market. 


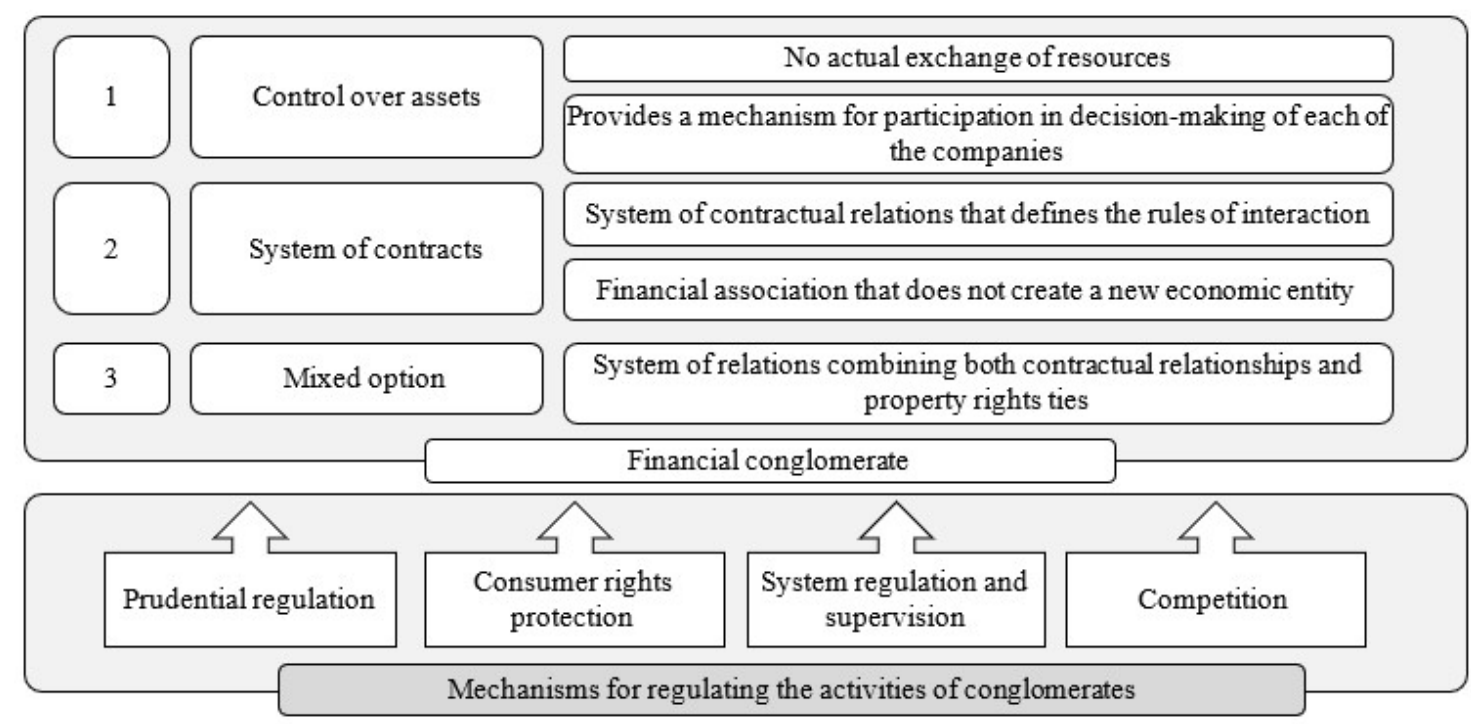

Figure 4. Methods for creating and regulating the activities of financial conglomerates

\section{Methodology}

The processes of globalization in the world economy have affected both the real and financial sectors. Globalization itself has become a new challenge to the traditional strategic business models of corporations, which has led to the need to seek and create unique competitive advantages at the international level. New realities, and the transformation of the perception of traditional fields of activity, have led to the need for modification in various sectors of the financial services market. Competition at the international level has become a powerful driver of this change.

A global trend in the processes of modification of sectors of the financial services market is the process of ever-increasing interpenetration by different participants from different sectors of the financial market to its other segments - financial convergence.

Method for determining the presence of convergence between the subjects of the financial market.

Considering the issue of financial convergence as a mechanism for modifying the sectors of the world financial services market, one should take into account the need for a methodology to determine the trends of its appearance among financial market participants. For these purposes, it is most expedient to use the sigma convergence indicator, the dynamics of which will indicate a decrease or increase in time dispersion (spread in time) of indicators of the development of financial conglomerates in the sample. Taking into account the fact that the nature of financial conglomerates, namely the scale of their activities, differs in individual sectors of the financial market, the coefficient of variation is more appropriate, the values of which, unlike the variance indicators, will not be affected by these scales.

$$
\begin{aligned}
& \sigma-\text { convergence } \\
= & \sigma t(Y t \ldots Y n) /(\text { mean } t(Y t \ldots Y n)) \\
\times & 100
\end{aligned}
$$

where $\sigma t$ is the standard deviation (square root of the variance of the random variable);

$Y$ is the indicator in the analyzed arrays;

mean $t(Y t \ldots Y n)$ is the average value of the indicator for a certain period of time.

The economic interpretation of this indicator is that the closer the sigma convergence indicator is to zero, the higher the convergence, since a sufficiently large value of the standard deviation shows a large scatter of values in the presented set with a specific average value of the set; a small $\sigma t$ value, accordingly, indicates that the values in the set are closely grouped around the mean.

\section{Experiment and Analysis of Results}

The pension segment of the financial market, along with the insurance segment, is one of the fastest-growing sectors of the global financial system, and in the coming years, the dynamics of their development will only grow. The financial convergence of the pension and insurance sectors of the global financial market is leading to significant changes in the entire landscape of the global financial system. In recent years, financial intermediaries represented by insurance corporations and pension funds have significantly increased their influence in the global financial market, acting as strategic investors. They have the opportunity to stabilize the financial system of developed countries and accelerate the formation of stock markets in countries with economies in transition.

The purpose of the experiment will be an empirical analysis of financial convergence using the sigma-convergence methodology of insurance 
corporations and pension funds, which, according to the proposed hypothesis, being large international investors, should demonstrate convergence in some fundamental performance indicators.

The choice of regions and countries for the experiment was dictated by their role in the global financial market since the American and European financial markets are world leaders, and the Asian market has shown active growth rates in recent years, not least thanks to China.

For the purposes of the experiment, the leading insurance companies and the largest pension funds were selected, for the analysis 12 American companies, 10 European and 8 Asian companies, a total of 15 insurance companies and 15 pension funds were selected. Data for the analysis were used from annual financial statements in the study period from 2012 to 2019.

To calculate the sigma convergence, the ratio of reserves to assets was selected. The reserves of insurance companies and pension funds are of a dualistic nature. On the balance sheet of insurance companies, reserves are reflected in the liabilities column and from this point of view, and reserves are not income. Still, they are temporarily free working capital of a special nature. Insurance companies need these funds to ensure payments on current obligations.

For pension funds, reserves are also necessary, they are of a technical nature, and serve to ensure that the fund fulfils its obligations for retirement benefits of clients, and are formed from receipts to pension accounts. At the legislative level, the ways of using reserves are rigidly fixed - they are used only to pay insurance benefits, index pension accounts, and their investment must be carried out in strict accordance with the country's insurance supervisory authorities.

Assets used to cover reserves, in turn, must meet the conditions for diversification, repayment, profitability and liquidity. It is worth noting that part of the resources in assets characterizes the strategy of each of the companies in relation to the degree of admission of risks on insurance portfolios to equity capital.
The calculation formula:

$$
\text { Share of } R \text { in } A=(\text { Reserves }) / \text { Assets }
$$

Summing up, it can be noted that the greater the value of the coefficient and its growth in dynamics, the higher the financial stability of an insurance company or a pension fund in terms of providing insurance coverage.

The calculation data for the dynamics of sigma convergence for pension funds and insurance companies are presented in Table 1 and Fig. 5.

A study of the activities of pension funds and insurance companies in the United States, the European Union and Asia, in terms of the ratio of reserves to assets, recorded a clear tendency towards increasing financial convergence.

The calculations made clearly show that the insurance sector of the international financial market is more susceptible to convergence; at the same time, convergence processes are traced in the pension segment. It should be noted the transformation of the financial market sectors by funds of pension plans based on certain payments towards programs based on specific contributions. The purpose of this transformation is to transfer additional coverage of investment risk in the context of flatness of financial markets. Government regulators are carrying out pension reforms and are also seeking to transfer corporate risks to the individual level, which indicates the transformation of the pension services sector, under the influence of convergence processes.

The analysis made it clear that insurance markets are the most converged, on the other hand, pension markets, under the influence of ongoing pension reforms, also tend to intensify convergence processes due to increasing competition and the desire to reduce potential risks.

A more vivid manifestation of convergence in insurance markets is also because the insurance portfolios of life insurance companies are more optimized and depend not only on the segment of the company's work but also on the structure of insurance payments for each type of insurance, forcing the company to revise its insurance portfolio in favour of more stable ones.

Table 1. Specific data of Column/Row

\begin{tabular}{|c|c|c|c|c|c|c|c|c|}
\hline Funds and insurance companies & 2012 & 2013 & 2014 & 2015 & 2016 & 2017 & 2018 & 2019 \\
\hline Asia pension Funds & 1,7 & 1,6 & 1,8 & 1,7 & 1,1 & 0,9 & 0,7 & 0,55 \\
\hline Asia insurance corporations & 1,4 & 1,3 & 1,1 & 1,05 & 0,85 & 0,65 & 0,5 & 0,35 \\
\hline USA pension Funds & 2 & 1,9 & 1,75 & 1,8 & 1,6 & 1,5 & 1,45 & 1,4 \\
\hline USA insurance corporations & 0,7 & 0,65 & 0,6 & 0,55 & 0,5 & 0,45 & 0,4 & 0,35 \\
\hline EU pension funds & 1,7 & 1,8 & 1,85 & 1,75 & 1,6 & 1,55 & 1,4 & 1,45 \\
\hline EU insurance corporations & 0,6 & 0,8 & 0,75 & 0,7 & 0,65 & 0,6 & 0,65 & 0,5 \\
\hline
\end{tabular}




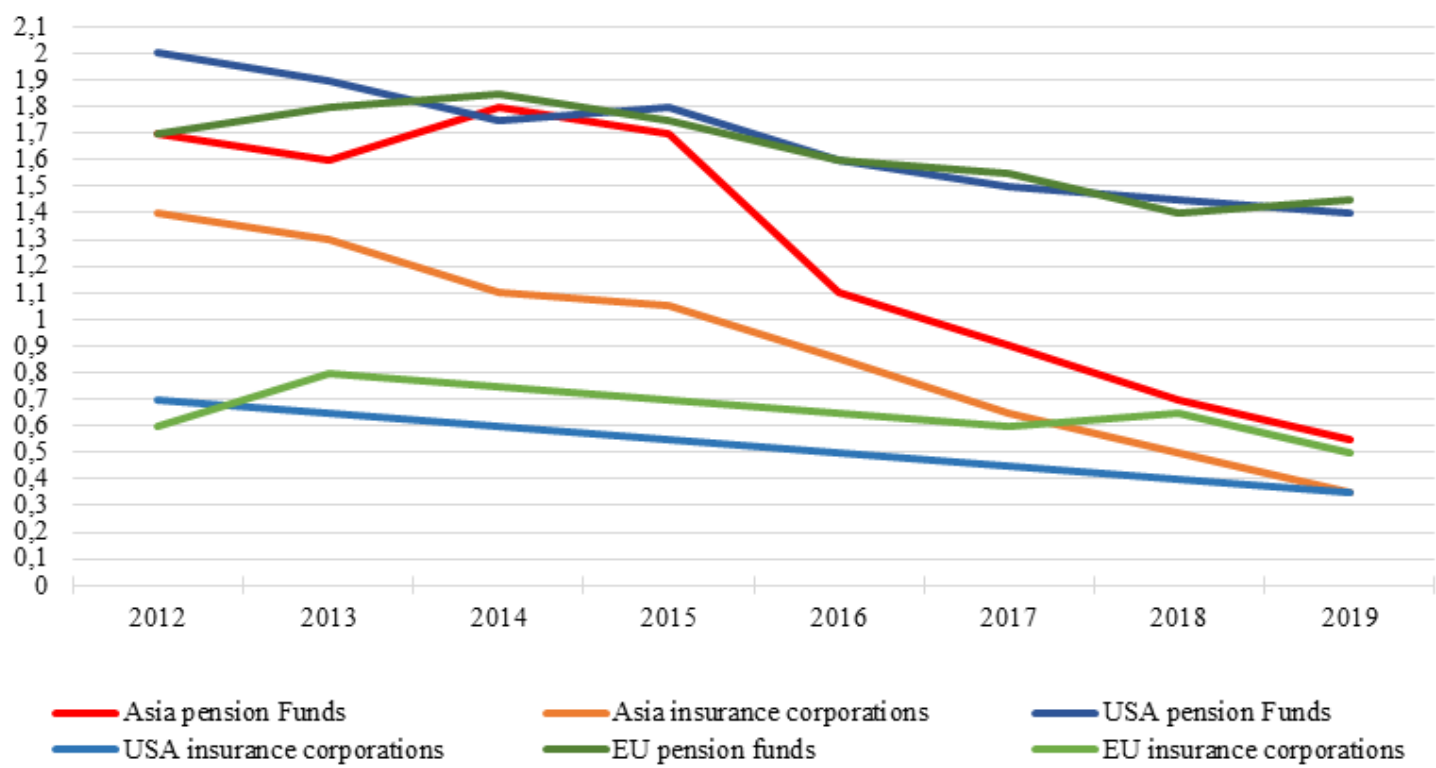

Figure 5. Dynamics of the sigma-convergence coefficient of pension funds and insurance companies by region

\section{Conclusions}

The globalization of modern economic systems, at present, has acquired the character of an inevitable process. The transition of competition from the national to the international level is forcing companies to look for ways to increase their competitive advantages. In light of the preceding, financial convergence of participants in various sectors of the international financial market manifests itself as a potentially strong argument in the competition.

Financial conglomerates, as the pinnacle of convergence in the financial market, seem to be both a field of great opportunities and a potentially risky direction. Obviously, close attention to these institutional formations will be riveted, both by state regulators and scientific researchers.

Financial convergence is a mechanism used to ensure both survival and change in the financial market. This area of scientific, economic thought provides a vast field for observation, research and experimentation.

\section{REFERENCES}

[1] Asongu S., "African Stock Market Performance Dynamics: A Multidimensional Convergence Assessment," Journal of African Business, Vol. 14, No. 3, 2013. DOI: 10.1080/1522 8916.2013.844043.

[2] Brada J. C., Kutan, A. M., Zhou S. "Real and monetary convergence between European Union's core and recent member countries: A rolling cointegration approach, " Journal of Banking and Finance, 29, pp. 249-270, 2005. DOI: 10.1016/j.jbankfin.2004.06.024.
[3] Calcagnini G., Farabullini F., Hester D. "Financial Convergence in the European Monetary Union?" SSRN Electronic Journal, 2000. DOI: 10.2139/ssrn.253358.

[4] Caporale G.M., Plastun A., Oliinyk V. "Bitcoin fluctuations and the frequency of price overreactions," Financial Markets and Portfolio Management, Vol. 33, No. 2, pp. 109-131, 2019. DOI: 10.1007/s11408-019-00332-5.

[5] Costantini M., Lupi C. "Stochastic convergence among European economies," Economics Bulletin, Vol. 3, No. 38, pp. 1-17, 2005.

[6] Elyasiani E., Mansur I., Pagano M. S. "Convergence and risk-return linkages across financial service firms," Journal of Banking and Finance, 31, pp. 1167-1190, 2007. DOI: 10.1016/j.jbankfin.2006.10.006.

[7] Gallizo J., Saladrigues R., Salvador M. "Financial Convergence in Transition Economies: EU Enlargement, " Emerging Markets Finance and Trade, 46(3), pp. 95-114, 2010. DOI: $10.2307 / 20750192$.

[8] Habshah Midi, Jama Mohamed, "A Modified Robust Support Vector Regression Approach for Data Containing High Leverage Points and Outliers in the Y-direction," Mathematics and Statistics, Vol. 8, No. 5, pp. 493-505, 2020. DOI: $10.13189 / \mathrm{ms} .2020 .080502$.

[9] James B. Edwards, Timothy L. Baker "The Outlook as Financial Convergence Falters, " Journal of Corporate Accounting \& Finance, Vol. 25, No. 6, pp. 13-21, 2014. DOI: 10.1002/jcaf.21983.

[10] Miraj Javed, Wang Zhuquan. "Analysis of Accounting Reforms in the Public Sector of Pakistan and Adoption of Cash Basis IPSAS," Universal Journal of Accounting and Finance, Vol. 6, No. 2, pp. 47-53, 2018. DOI: 10.13189/ujaf.2018.060203.

[11] Mura, L., Buleca, J., Hajduova, Z., Andrejkovic, M. "Quantitative financial analysis of small and medium food enterprises in a developing country, " Transformations in Business and Economics, 14(1), 2015. pp. 212-224. 
[12] Osodlo V.I., Perepeliuk T.D., Kovalchuk O.P., Osadchenko I.I., Vintoniak V.F. "The development of professional motivation of the activity subject under specific conditions, " Journal of Intellectual Disability - Diagnosis and Treatment, 8(2), pp. 196-204, 2020. DOI: 10.6000/2292-2598.2020.08. 02.15 .

[13] Su Y.-C., Huang H.-C., Hsu M.-W. "Convergence to market efficiency of top gainers," Journal of Banking and Finance, 34, pp. 2230-2237, 2010. DOI: 10.1016/j.jbankfin.2010.02. 006.
[14] Sylvia Maxfield, W. Kindred Winecoff \& Kevin L. "Young An empirical investigation of the financialization convergence hypothesis," Review of International Political Economy, 24:6, pp. 1004-1029, 2017. DOI: 10.1080/09692 290.2017.1371061.

[15] Yiannis Yiannoulis. "Literature Review on the Hellenic Auditing and Accounting Environment before, during and after the Crisis Period," Universal Journal of Accounting and Finance, 7(2), pp. 43-49, 2019. DOI:10.13189/ujaf.201 9.070202 